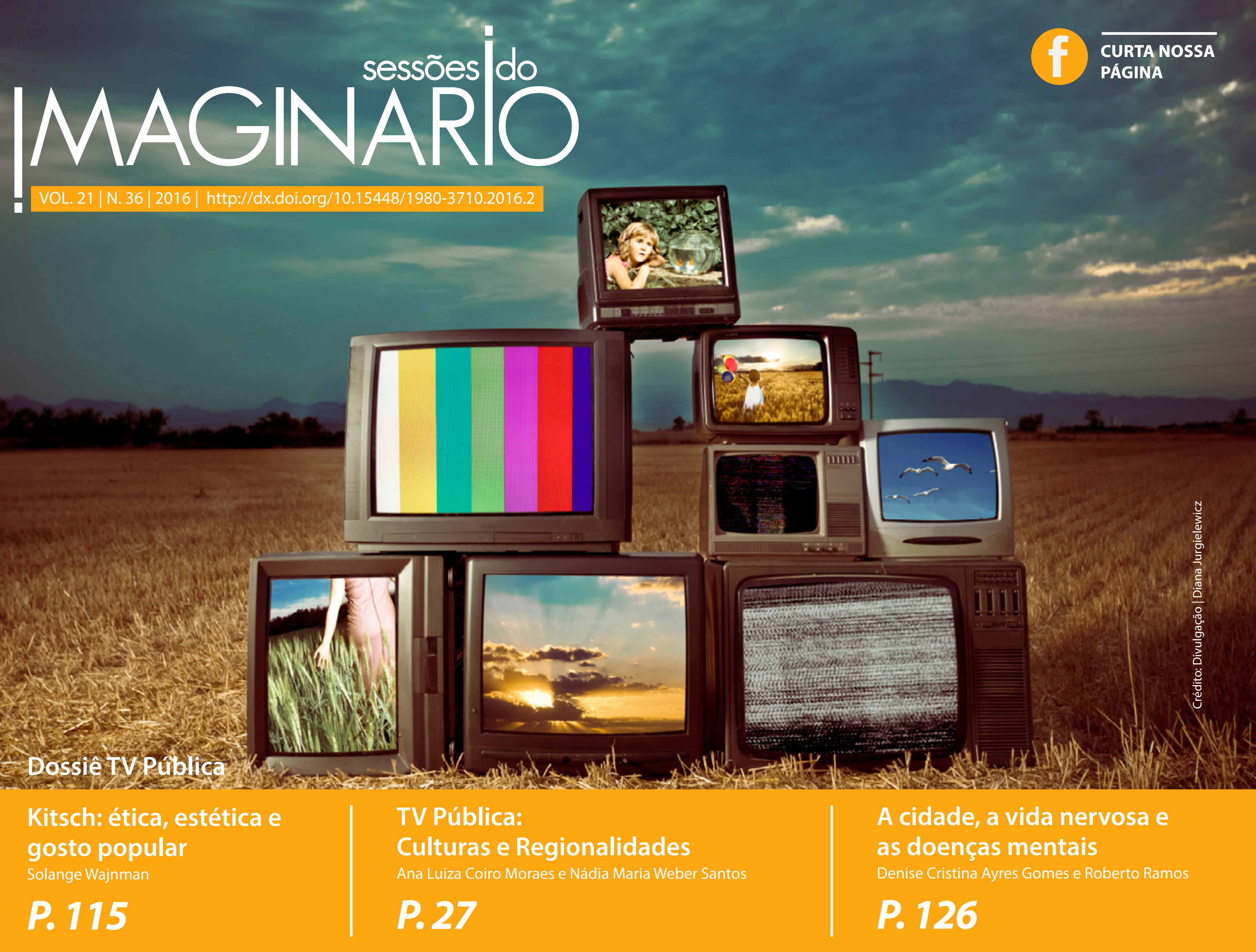




\section{A Semana de Comunicação Pública de Pernambuco como estratégia de articulação e relacionamento das emissoras da UFPE}

\section{Public Communication of \\ Pernambuco Week as an articulation \\ strategy and relationship of \\ broadcasting stations in the \\ Federal University of Pernambuco}

Patrícia Horta Alves ${ }^{2}\left[\right.$, Felipe Peres Calheiros ${ }^{3}[$

\section{DOSSIÊ}

56 PORTO ALEGRE | v. 21 | n. 36 | 2016 | pp. 56-65 DOI: http://dx.doi.org/10.15448/1980-3710.2016.2.25661 Sessões do Imaginário

\section{Resumo}

O artigo apresenta um estudo sobre a Semana de Comunicação Pública de Pernambuco, realizada anualmente desde 2013 pelo Núcleo de TV e Rádios Universitárias (NTVRU) da Universidade Federal de Pernambuco (UFPE). O texto traça um panorama do evento e mostra como a organização conseguiu estrategicamente expandir as atividades, em parceria com cursos de comunicação social de Recife, Olinda e Caruaru, para atingir um público expressivo de profissionais, professores e estudantes. A partir do recorte do conceito de comunicação pública como sistema de radiodifusão, associado à lei complementar 11.652/08, uma análise das três edições da Semana tenta entender como as decisões de divulgação e realização causaram impacto para o alcance do evento.

\section{Palavras-chave}

Comunicação pública; radiodifusão; democracia; mídia.

\section{Abstract}

This article presents a study about the Public Communication of Pernambuco Week, held annually since 2013 by the TV and Radio Center of the Federal University of Pernambuco. The text provides an overview of the event and shows how the organization strategically expanded the activities - through partnership with media courses from the cities of Recife, Olinda and Caruaru - to reach a significant audience of professionals, teachers and students. From the concept of public communication and broadcasting system, supported by Brazilian federal law (number 11.652 from 2008), an analysis of three editions of the event intend to elucidate how publicity and realization decisions impacted on the success of the event.

\section{Keywords}

Public Communication; broadcasting; democracy; media. 
Breve contexto histórico do Núcleo de TV e Rádios da UFPE

$\mathrm{Na}$ América Latina e no Brasil, quarenta anos depois do surgimento da rádio educativa, as primeiras emissoras de TV com esse viés foram inauguradas no fim da década de 1960, num período de intensa industrialização no continente. A radiodifusão passou a ser vista pelos governos nacionais - em sua maioria, guiados por regimes ditatoriais - como instrumento de ampliação da educação da população e assim nasceram as primeiras experiências de comunicação de massa distintas das práticas comerciais, também em terras brasileiras.

Fundada em fins de 1968, primeira emissora educativa brasileira, a TV Universitária de Pernambuco nasceu incorporada ao sistema de radiodifusão da Universidade Federal de Pernambuco (UFPE), que até então somente possuía a rádio Universitária AM, criada em 1963. Surgiu ali o Núcleo de TV e Rádios Universitárias (NTVRU), órgão suplementar da UFPE ao qual também se agregou em 1979 a rádio Universitária FM. Estruturado a partir da prática de uma comunicação estatal de concepção educativa e elitista, o Núcleo vinculou-se, em seus primórdios, aos interesses políticos da época, à influência dos docentes e ao poderio da elite econômica e cultural local, o que garantiu fartos investimentos e contratações nos seus primeiros anos (Angeiras, 2015, p. 91).

Assim como a definição elitista, a educativa parte da premissa de que a mídia eletrônica constitui mecanismo fundamental de difusão de conteúdos perante a população. O que diferencia a primeira da segunda é a ênfase, decorrente de sua mani- a formulação de um projeto totalizante pela necessidade de resposta às demandas simbólicas da população em um ambiente de monopólio estatal. O lema 'informar, divertir, educar' sintetiza em três propósitos a amplitude do projeto, que por mais impositivo que fosse não poderia abrir mão da sedução proporcionada pelo entretenimento na programação. Já os representantes da corrente aqui denominada 'educativa' viam na mídia pública um instrumento de ampliação da formação da população (Intervozes, 2009, p. 29).

Apesar dos investimentos iniciais, a diminuição de recursos e contratações de profissionais para o NTVRU pela UFPE ao longo das décadas de 1970 e 1980 repercutiu para o crescente sucateamento das instalações e equipamentos e a desatualização das equipes, salvo alguns curtos e raros períodos de exceção. Durante os anos 1990, as decisões de ordem política e macroeconômica, que aproximaram o estado brasileiro do modelo neoliberal, reduziram ainda mais os quadros e os recursos para a educação superior pública, e as consequências foram fortemente sentidas também pelo Núcleo, o qual já não figurava entre as prioridades políticas da Universidade.

No começo dos anos 2000, diante da situação de desmonte das Universidades Federais Brasileiras, como consequência da política federal de redução do quadro docente e técnico e precarização das condições de trabalho, verificou-se a ampliação do número de Fundações de direito privado ligadas a autarquias de ensino superior da União. Com maior flexibilidade administrativa e financeira, as Fundações facilitavam a captação de recursos para diversas atividades, projetos e cursos, bem como permitiam compras sem licitação e o pagamento a docentes, técnicos e terceiros, pela prestação de serviços. Nesse contexto, firmaram-se diversos convênios entre empresas, o NTVRU e a FADE Fundação de Apoio ao Desenvolvimento da UFPE - para a contratação de espaços de veiculação e publicidade na grade das emissoras e para a produção e transmissão de programas realizados por servidores e terceiros (Ferreira Neto, 2012). O artifício transformou bastante a programação das rádios e da televisão universitárias, afastando-as da estrita concepção educativa e aproximando-as da realidade do mercado da comunicação comercial local. Essa fase durou até 2008, quando foi proferida sentença pela justiça federal proibindo a veiculação de publicidade comercial nos veículos da UFPE. Mesmo tentando recorrer em instâncias superiores, a UFPE acatou a decisão judicial e diversos programas tiveram de sair do ar, tendo o NTVRU perdido cerca de um terço de sua equipe, com a demissão dos prestadores de serviços contratados diretamente através da FADE.

O fim da "era FADE" abriu uma nova lacuna na gestão das emissoras do Núcleo, ainda mais sucateadas, sem recursos nem equipes para ocupar minimamente os espaços da programação local. E após testemunhar a passagem pouco relevante de três diretores gerais em apenas cinco anos, a equipe do NTVRU aderiu intensamente à greve dos servidores públicos federais de 2012, interrompendo por cinco dias a transmissão da TVU Recife - um fato inédito. A pressão feita pelos técnicos surtiu o efeito desejado, forçando a abertura pela reitoria da UFPE de um processo coletivo de indicação da nova diretoria e formulação do primeiro planejamento estratégico para o órgão. $O$ documento, produzido a várias mãos nesse período, definiu a mis- 
são e a visão do NTVRU, como respectivamente dispõe o site do Núcleo:

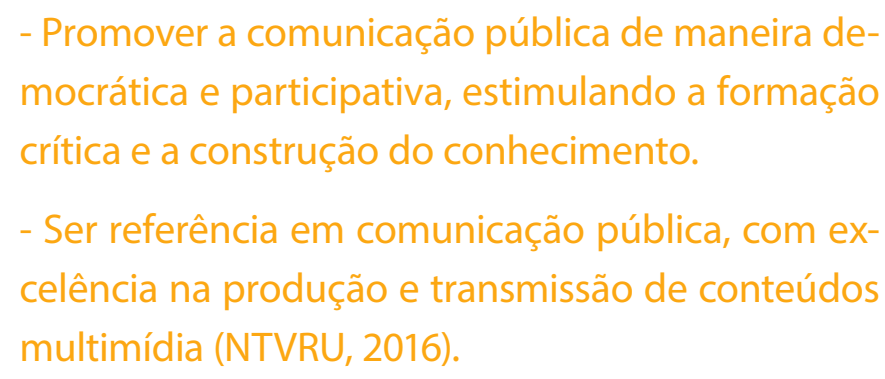

Pela primeira vez, a comunicação pública foi reconhecida de modo institucional na UFPE como papel do Núcleo. Uma escolha decorrente do fortalecimento e da divulgação crescente dessa concepção de comunicação que, apesar de historicamente praticada em diversos países, ainda hoje é uma novidade tardia no Brasil. A eleição de um governo federal mais próximo dos movimentos sociais e dos direitos humanos em 2002 estimulou a criação de políticas públicas e espaços de discussão, tais como a I Conferência Nacional de Comunicação (Confecom) em 2009. Durante o encontro, entre outras coisas, elegeu-se como prioridade o investimento na Empresa Brasil de Comunicação (EBC). Criada em 2007, a EBC assumiu a gestão dos canais de rádio e TV outorgados à União Federal, com a missão de formar uma Rede Pública de Rádio e TV, respeitando princípios e diretrizes previstos na lei 11.652/08 e inaugurando finalmente a primeira tentativa de radiodifusão assumidamente pública não-estatal no Brasil.

A Empresa Brasil de Comunicação (EBC) surgiu para fortalecer o sistema público de comunicação, é

\begin{abstract}
gestora dos canais TV Brasil, TV Brasil Internacional, Agência Brasil, Radioagência Nacional e do sistema público de Rádio - composto por oito emissoras. Possuem independência editorial, distinguindo-se dos canais estatais ou governamentais, com conteúdos diferenciados e complementares aos canais privados. Sua finalidade é complementar e ampliar a oferta de conteúdos, oferecendo uma programação de natureza informativa, cultural, artística, científica e formadora da cidadania (EBC, 2016).
\end{abstract}

O contexto nacional favorável e a pesquisa do tema da comunicação pública por parte de alguns técnicos do núcleo influenciaram o processo de elaboração do planejamento estratégico de 2013-2015 do NTVRU, repercutindo para um novo entendimento em relação às atividades a serem desenvolvidas, principalmente no que se refere à relação com a sociedade civil. Nesse sentido, adicionou-se ao organograma mais um setor denominado Assessoria de Articulação e Fomento (AAF), que substituiu a antiga Gerência de Apoio Cultural e Veiculação, com o objetivo de dar conta da dívida histórica da UFPE a respeito da participação e do controle social nas emissoras da UFPE.

\section{A Semana de Comunicação Pública de Per- nambuco como estratégía de articulação}

Uma das principais conquistas dos movimentos nacionais pelo direito à comunicação foi a inclusão do tema "Da comunicação social" na Constituição Federal de 1988. Alguns direitos fundamentais ficaram protegidos e outros assuntos finalmente receberam o devido tratamento através de sua inserção na carta magna. Um deles, o princípio da complementaridade - artigo 223 - preceitua que a comunicação deve ser composta por três sistemas: o estatal, o público e o privado. No entanto, problema vivido por quase todos os tópicos do capítulo V do Título VIII, não há até hoje leis para regulamentação dessas previsões constitucionais especificamente. Com o artigo 223 não ocorreu algo diferente, e somente o sistema público, depois de vinte anos de Constituição Federal, teve sua legislação complementar promulgada, a lei 11.652/08.

O sistema ou serviço público de radiodifusão pode ser compreendido como "a radiodifusão realizada, financiada e controlada pelo público e para o público. Não é comercial nem estatal; é isento de ingerência política e pressões de correntes comerciais" (Mendel; Solomon, 2011, p. 37). Seguindo essa definição, a lei da radiodifusão pública estabelece o controle social e a participação social como alguns dos princípios a serem seguidos por todas as emissoras públicas brasileiras. De forma que a decisão política da UFPE de cumprir o previsto em lei e assumir suas emissoras como públicas lançou também o NTVRU diante do desafio de estreitar o relacionamento transparente e republicano com a sociedade civil, abrindo possibilidades de acesso à produção de conteúdo para a veiculação nos canais e convidando à tomada de decisão a respeito da programação e do conteúdo. A lei 11.652/08 preceitua em seu art. 20:

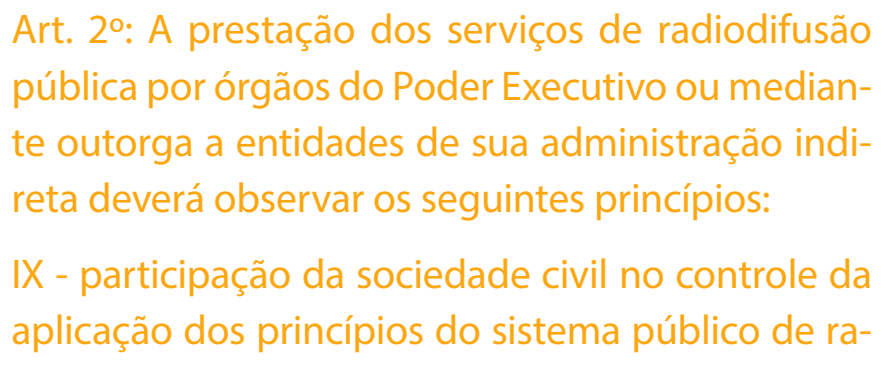


diodifusão, respeitando-se a pluralidade da sociedade brasileira (Brasil, 2016).

A Assessoria de Articulação e Fomento (AAF) foi criada em 2012, diretamente ligada à direção geral e com o objetivo de estimular o estreitamento dos laços com a sociedade pernambucana dentro e fora da comunidade acadêmica da UFPE, através de ações previstas pelo próprio planejamento estratégico do
NTVRU para 2012-2015, como: a criação de normas para a captação de recursos pelos produtores locais através do apoio cultural, elaboração de editais de fomento à produção independente de conteúdo, a realização de audiências públicas sobre a programação dos veículos, a publicização de procedimentos para a proposição de novos programas por produtores externos, e o estreitamento da relação com o Departamento de Comunicação da UFPE e outros espa-

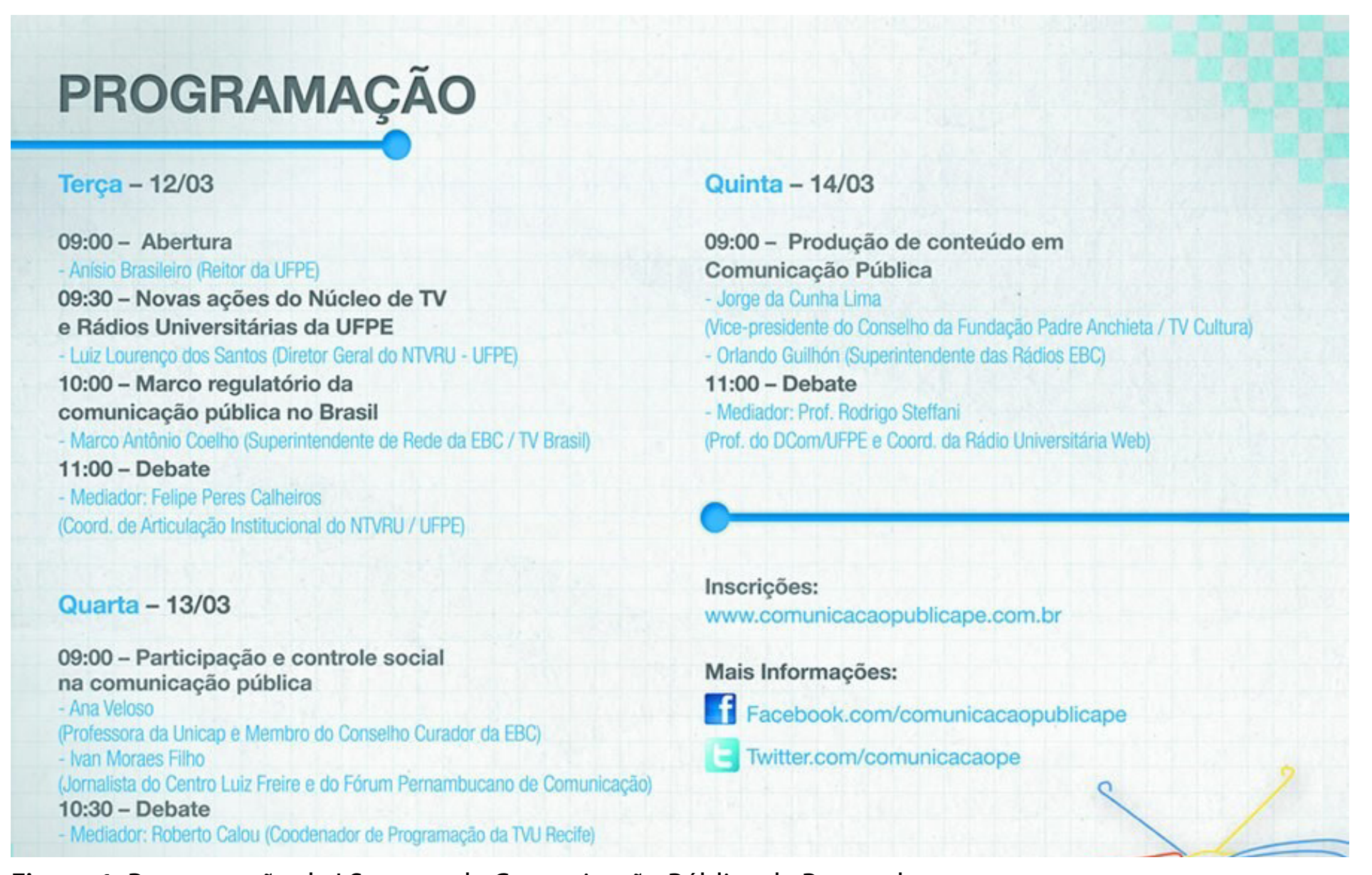

Figura 1: Programação da I Semana de Comunicação Pública de Pernambuco.

Fonte: Os autores. ços de formação, tendo em vista a inserção direta das emissoras no contexto de educação superior pública.

Para o cumprimento dessa última missão, coube à AAF primeiramente aproximar-se dos docentes e estudantes da UFPE, frequentando algumas reuniões de pleno, incentivando a visita de alunos e pesquisadores, e oferecendo disciplinas dos cursos de Rádio, TV e Internet dentro das dependências do Núcleo - prática esquecida há décadas. Um outro objetivo do setor era o da realização de um evento anual que pudesse colocar em discussão assuntos relativos à teoria e à prática da comunicação pública. O foco seria o convite a pesquisadores, profissionais e ativistas de relevância local, nacional, e internacional, que pudessem aprofundar esse debate com estudantes, professores, profissionais e sociedade civil de Pernambuco, envolvendo o máximo de pessoas com a realização da comunicação pública.

Dessa forma, ainda no primeiro mês da nova gestão, em dezembro de 2012, começou a ser concebida a I Semana de Comunicação Pública de Pernambuco, realizada três meses depois, em março de 2013. Toda a preparação e escolhas das mesas dessa primeira edição ficaram a cargo do recém-empossado corpo gestor do NTVRU, devido à falta de tempo para o envolvimento de outros atores interessados. O apoio dentro da própria UFPE, em diferentes Pró-reitorias, e da TV Pernambuco - a outra TV pública local, ligada ao Governo de Pernambuco - desde o começo, mostrou-se fundamental à viabilização de passagens, de serviços e materiais de divulgação, o que se repetiria nas outras duas edições do evento.

Em três dias, foram realizadas três mesas planejadas para dar conta estrategicamente de alguns recortes fundamentais à apropriação de forma geral 
do tema da radiodifusão pública. Na abertura, foi feita uma apresentação da nova proposta de gestão do NTVRU, pelo diretor-geral, e uma discussão histórica e política sobre o marco regulatório da comunicação pública e sua trajetória de construção, com o superintendente nacional de Rede da EBC, a fim de garantir uma presença política da rede pública de TV e ao mesmo tempo oferecer conteúdo relevante para os que desconhecessem o assunto. No segundo dia, o foco foi o debate sobre a participação e o controle por parte da sociedade civil, que contou com pesquisadores e ativistas locais de projeção nacional, com o objetivo de incentivar a comunidade local a se aproximar e exigir o espaço que lhe deve ser por direito garantido nas emissoras públicas. E no terceiro e último dia, garantiu-se a discussão aprofundada a respeito do conteúdo de interesse público com dois profissionais de relevância internacional, um deles gestor durante os anos 1980, época mais frutífera da Fundação Padre Anchieta, e o outro, superintendente de rádios da EBC e ativista histórico da Associação de Rádios Públicas do Brasil (ARPUB).

O evento ocorreu no auditório do Centro de Filosofia e Ciências Humanas, localizado entre o Centro de Educação e o Centro de Artes e Comunicação da UFPE, numa espécie de pool das ciências humanas, cultura e linguagens do campus Recife, o que facilitou a participação do público estudantil e docente, de forma geral mais interessado no assunto dos debates.

A I Semana contou com o uso de material impresso, perfis em redes sociais, veiculação de peças nos intervalos da TVU Recife e Universitária FM e site para inscrição, divulgação da programação, currículo dos palestrantes e disponibilização de fotos do evento. Não se pode quantificar o número de pessoas alcança- das através da rádio e da TV, pois não há e nem havia mensuração de audiência dos veículos, mas é possível dimensionar o alcance através das redes sociais, principalmente do Facebook do evento. Estima-se, segundo dados fornecidos pelo próprio Facebook, que um total de 10 mil pessoas acessaram as postagens de divulgação, havendo 591 inscritos através do site e cerca de 300 participantes durante os três dias do evento.

Estudantes do curso de rádio, TV e Internet realizaram entrevistas com os convidados e participantes, com o apoio do laboratório da imagem e do som do Departamento de Comunicação, para compor uma série de interprogramas sobre comunicação pública que circulou por muito tempo na TVU Recife e no canal da emissora no YouTube. Além disso, também foi produzida uma matéria para a TV durante o dia de abertura, além da peça de divulgação da Semana que foi ao ar na TVU Recife e na Universitária FM na quinzena que antecedeu o evento. Também houve a transmissão on line das mesas do evento e uma edição especial do programa de debates Opinião Pernambuco, veiculado em horário nobre foi ao ar ao vivo com alguns convidados do evento pela TVU Recife para toda a região metropolitana.

Uma semana após a conclusão, foi feita uma avaliação do evento junto aos servidores do NTVRU, a partir de sugestões de participantes da Semana e das percepções dos presentes. Além do diagnóstico de uma participação tímida dos técnicos do Núcleo, apontou-se a necessidade de oferecer acessibilidade às palestras através da contratação de intérpretes de libras, bem como a produção de mais conteúdos para a repercussão nos veículos de radiodifusão do NTVRU. Alertou-se também para a importância de dedicar o evento estritamente à discussão do tema da comunicação públi- ca de forma mais intensa, evitando a espaços para assuntos institucionais do NTVRU nas edições seguintes.

Se em 2013 o objetivo da AAF de aproximação com os produtores independentes foi conquistado através da institucionalização de procedimentos de solicitação de cartas de interesse de veiculação de programas e da realização de audiências públicas sobre a programação dos veículos, no ano seguinte estava posto o desafio de relacionar-se com os espaços de formação da UFPE para a oferta de disciplinas na sede do Núcleo e a concretização de parceiras entre o NTVRU e o Departamento de Comunicação (DCom). E de fato, em 2014, foram oferecidas as disciplinas de Teleducação e de Comunicação Pública, dentro das dependências do NTVRU, com estudantes e docentes passando a frequentar semanalmente o núcleo com a finalidade de assistir às aulas, praticar e estar mais perto da produção de conteúdo.

A articulação com o Departamento de Comunicação (DCom) influenciou também a elaboração da II Semana de Comunicação Pública de Pernambuco, assinada pelo NTVRU e pelo Departamento, e realizada no Centro de Educação, na tentativa de envolver novo público com o assunto, mas manter-se próximo fisicamente do Centro de Artes e Comunicação e do Centro de Filosofia e Ciências Humanas. Finalmente os técnicos do sistema de radiodifusão pública da UFPE junto com os docentes e estudantes de comunicação social organizavam um evento de discussão prática e teórica a respeito da comunicação pública.

Essa realização conjunta repercutiu para a formação das mesas e escolha dos convidados. Seguindo recomendação da avaliação da primeira edição, optou-se por uma primeira mesa de abertura que contaria 
Figura 2: Programação da II Semana de Comunicação Pública de Pernambuco. Fonte: Os autores.

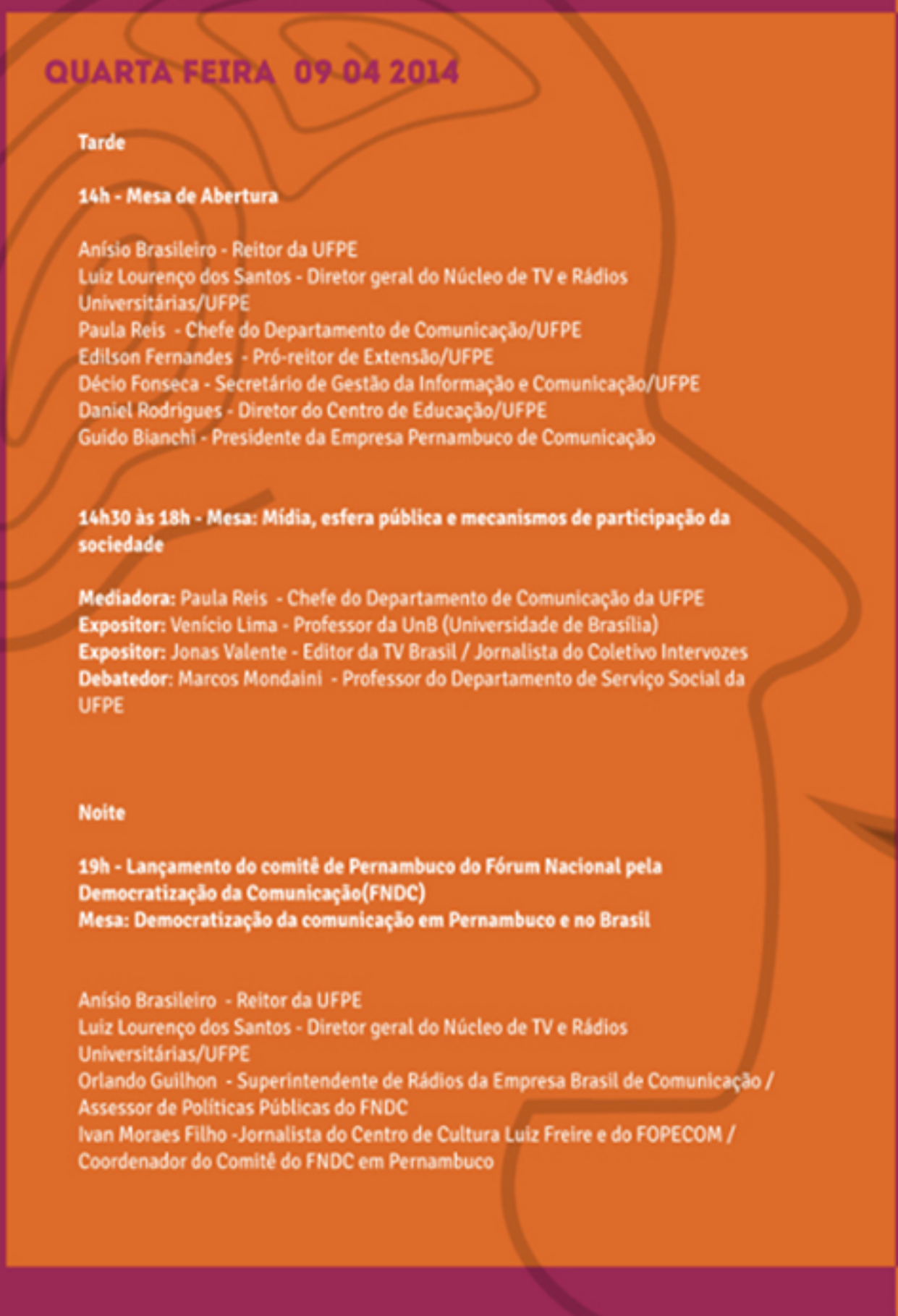

Manhas

09 às $13 \mathrm{~h}$ - Oficinas

(Solas do Departamento de Comunicaçio, no CAC/UFPE):

1) Politicas públicas de comunicaça

Patricia Horta - Professora do Departamento de Comunicaç dio da UFPE

2) Produşà audiovisual independente

Paulo Sano - Realizador Coletivo Asterisco / Editor de Imagens do LIS/DCom

3) Lei da mídia democrática

van Moraes - Jornalista do Centro de Cultura Luiz Freire e do FOPECOM

4) Documentário e direitos humanos

Fernando Weller - Professor do Departamento de Comunicaça da UFPE

Tarde

16h30 às $18 \mathrm{~h}$ - Mesa: Formaçào politica e sociedade mediatizada

Mediador: Ana Paula Lucena - Professora da Faculdade Senac/PE

Expositor: Edgard Rebouças - Professor da UFES (Universidade Federal

do Espirito Santo)

Expositora: Rosa Sampaio - Coordenadora do Programa

So pra fazer midia/ Aucuba

Debatedor: Antonio Alves - Realizador / Coletivo Gambiarr

\section{SEXTA FEIRA 11042014}

Manhs

09h00 às 13h - Mesa: Programaçảo e conteúdo das emissoras públicas

Mediadora: Gorete Linhares - Coordenadora de Conteúdo do NTVRU/UFPE Expositora: Gabriela Borges - Professora da UFJF (Universidade Federal de Juiz de Fora) Expositora: Valci Zuculoto - Professora da UFSC (Universidade Federal de Santa Catarina) Debatedora: Ana Veloso - Professora da UNICAP (Universidade Catolica de Pernambuco) / Membro do conselho curador da Empresa Brasil de Comunicaçáo

61 PORTO ALEGRE | v. 21 | n. 36 | 2016 | pp. 56-65 Sessões do Imaginário 
com todas as representações políticas das instituições organizadoras, como diretor geral do NTVRU, chefe do DCom, reitor e Pró-reitores. Repetindo o evento anterior, foram pensadas mesas para três dias, mas dessa vez em horários variados, para atender a mais pessoas. A segunda mesa dedicou-se à discussão sobre a esfera pública e a participação da sociedade, com dois pesquisadores/ativistas de relevância nacional, continuando o debate iniciado em 2013 e colaborando com o interesse do NTVRU de aprofundar o tema com o público a fim de instituir naquele ano o seu conselho curador de programação. Na terceira mesa, na noite do mesmo dia, aconteceu o lançamento do Comitê do Fórum Nacional pela Democratização da Comunicação em Pernambuco (FNDC), revelando o comprometimento do NTVRU, do DCom e do evento com a pauta dos movimentos pelo direito à comunicação. No segundo dia, realizaram-se oficinas pela manhã - uma novidade muito procurada e bem aceita principalmente pelos estudantes - e uma mesa pela tarde, dedicada ao tema da formação política e a relação com a mídia, composta por ativistas locais com larga experiência em comunicação comunitária e audiovisual. E no último dia, pela manhã ocorreu a quarta mesa sobre programação e conteúdo das emissoras públicas, com duas pesquisadoras brasileiras que apresentaram estudos aprofundados sobre rádio e televisão públicas no Brasil e no mundo.

Todas as mesas contaram com intérprete de libras e foram transmitidas ao vivo pela internet. Foram produzidas duas matérias, uma pela Assessoria de Comunicação da UFPE e outra pela TVPE, veiculadas nas emissoras e disponibilizadas no YouTube. A realização de programas, coberturas e veiculações sobre o evento ficaram prejudicadas pela ausência de técnicos, em greve no NTVRU e na UFPE.

Apesar das mesmas estratégias de divulgação e apoio se repetirem e se intensificarem em relação a 2013, incluindo o apoio de entidades interessadas na promoção da discussão e o envolvimento de docentes na organização do evento, a ocorrência de uma greve dos técnicos da UFPE, associada à pequena articulação com as disciplinas do DCom e os estudantes do Centro de Educação, levaram à frustração das expectativas de público. Com exceção das oficinas e das mesas do primeiro dia, houve um grave esvaziamento do evento. Não obstante a divulgação ter atingido cerca de 20 mil pessoas com postagens no Facebook, conforme dados da fanpage, apenas 187 pessoas do total de 500 inscritos compareceram, em 3 dias de atividades.

Além dos pontos acima, os organizadores, em reunião com técnicos, docentes e estudantes, avaliaram que seria interessante aumentar a produção de conteúdo sobre o evento nos próprios veículos, ampliar o número de oficinas, e principalmente que era preciso rever as estratégias de realização do evento em relação a local, período e horário, a fim alcançar com maior efetividade os profissionais, professores e estudantes de comunicação, público-alvo da atividade.

\section{Ill Semana de Comunicação Pública de Pernambuco: descentralização para ampliação da participação}

Ainda em construção no Brasil, o sistema público de comunicação enfrenta os diversos problemas decorrentes do desconhecimento e do desinteresse por boa parte da população, que de forma geral encontra dificuldades em acessar o conceito da radiodifusão pública, aliado ao aperfeiçoamento da de- mocracia. Na análise pela gestão do NTVRU, após o trabalho de envolvimento da produção independente e dos estudantes e docentes da UFPE, o próximo desafio seria a articulação com outros espaços de formação de comunicadores para que a oferta de disciplinas curriculares e debates a respeito da comunicação pública pudesse fomentar a mobilização dentro da própria categoria dos profissionais da radiodifusão em defesa da construção do sistema público.

Esse entendimento somou-se ao relativo fracasso de público na II Semana, indicando que o evento precisaria de um novo formato capaz de atingir mais pessoas e não depender somente da limitada equipe da AAF e seus parceiros de dentro da UFPE. Nada melhor nesse aspecto do que seguir o próprio conceito da comunicação pública de participação social e envolver mais outros atores na tarefa na organização do evento e na promoção da discussão. Descentralizar para um maior alcance e um maior envolvimento local. Foi a partir daí que se decidiu de forma diferente pela realização da empreitada de 2015 através de uma ampla articulação com os coordenadores e docentes de cursos de comunicação social das diversas instituições públicas e particulares de Recife, Olinda e Caruaru (a 120 km de Recife, no agreste pernambucano), para uma realização conjunta, descentralizada e que pudesse envolver mais temas, gente e olhares a respeito do assunto.

Para tanto, ainda em 2014, foram contatados pela AAF e pela direção geral do NTVRU os cursos de Comunicação Social do Centro Acadêmico do Agreste da UFPE, da AESO - Barros Melo, da UNICAP - Universidade Católica de Pernambuco, UNINASSAU e Faculdade Joaquim Nabuco e o curso técnico de rádio e TV do SENAC Pernambuco. Além de apresentar informações sobre o novo projeto do NTVRU, o 
ASSISTA AO VÍDEO

\section{口 Terça-feira 05/05/2015}

9h- Mesa 1 - "Regulamentar a midia para democratizar o Brasil" CAC/UFPE, - Abertura

Anisio Brasiteiro, Reitor da Universidade Federal de Pernambuco (UFPE) Emiliano José, Secretario Nacional de Serviços de Comunicaçăo Eletrônica do Ministério das Comunicaçōes

Rosane Bertotti, Coordenadora do Fórum Nacional pela Democratizaçăo da Comunikaçà (FNDC)

Nelson Breve, Presidente da Empresa Brasil de Comunicaço bo [EBC]

Paulo Camara, Governador do Estado de Pernambuce

Luiz Lourenço dos Santos, diretor do Núcleo de TV e Rádios Universitárias da UFPE

14h-Mesa 2- "Desafios téenicos e politicos na comunicaçăo pública na América Latina." CAC/UFPE

Edgard Rebouças(UFES)

Mariana Martins (EBC/UNB)

Aline Gomes (UFRN)

Mediadora: Paula Reis (UFPE)

19h - Mesa 3 - "Comunicação Pública, Editais e Produção Independente." UniNassau Mariana Porto (Associaçăo Brasileira de Documentaristas.PE)

Milenna Evangelista (Coordenadoria do Audiovisuat, Sec. Cultura PE)

Mediador: Marjones Pinheiro (UniNassau)

口. Quarta-Feira 06/05/2015

9 h - Mesa 4 - "Direitos Autorais e Comunicaçăo Pública" AESO

Luis Paulo Bogliolo Piancastell (Diretoria de Direito Intelectual/Minc)

Oriando Guilhon (EBC)

HD Mabuse (C E S AR.

Mediador: Alexandre Saldanha (AESO)

ㅁ Quinta-Feira 07/05/2015

9h - Mesa 5 - "Democratizaç̆o da midia e o profissional técnico de radio e TV" SENAC

Ivan Moraes Filino (Centro de Cultura Luiz Freire)

Cynthia Faiço (Massangana Multimidia/STiC-PE)

Mediador: Danilo Lúcio (SENAC)

$13 \mathrm{~h} 30$ - Apresentaçắo dos cursos de comunicaçắo social da UFPE em Caruaru e de jornalismo da Asces e da UniFavip - Caruaru: ASCES

Amilcar Bezerra (UFPE)

Christiane Boa Viagem (Asces)

Rosangela Araujo de Souza (Unifavip)
14 h30 - Mesa 6 - "A democracia, as redes sociais e o poder do cidad50" Caruaru: ASCES

Christianne Alcantara (Assembleia Legislativa de Pernambuco),

Socorro Macedo (Le Fil)

Sheila Borges (UFPE)

Tenaflae Lordêlo (Unifavip)

Mediador: Charles Leite (UFPE)

16 h30 - Mesa 7- "Saúde e Comunicaçăo Pública"

Caruaru: ASCES

Diego Gouveia (Faculdades Boa Viagem e Pernambucana de Saúde).

Patricia Horta (UFPE)

Rodrigo Cariri (UFPE)

Eduardo Melo (Asces)

Mediador: Amilcar Bezerra (UFPE)

19h - Mesa 8 - "Regulaçăo da Midia no Brasil" FJN

Andrea Trigueiro (UNICAP/Sindicato dos Jornalistas de Pernambuco)

Rosa Sampaio (Fórum Pernambucano de Comunicaça)

Mediadora Ivanice Lima (FJN) - Mediadora

Dexta-Feira 08/05/2015

14h - Mesa 9 - "Regulamentaçăo da midia: antigas batalhas e novos fronts" UNICAP

Luiz Carlos Pinto Junior (UNICAP)

Juliano Domingues (UNICAP)

Guido Bianchi (TVPE)

Mediadora: Andrea Trigueiro (UNICAP)

口 ENDEREÇOS:

CAC/UFPE- Auditório Evaldo Coutinho, Centro de Artes e Comunicaçăo da Universidade Federal, Cidade Universitária, Recife

AESO - Av. Tranzamazônica, 405, Jardim Brasil II, Olinda

UniNassau - Auditório Capiba, Bloco C, Rua Joaquim Nabuco, n⿳0 778, Derby, Recife ASCES - Auditório da Asces, Av. Portugal, 584, Bairro Universitário, Caruaru SENAC - Av Visconde de Suassuna, 0500 . Auditório Roberto Régnier, Santo Amaro, Recife

Amaro, Recife
UNiCAP - Auditório G2 Rua do Principe, 526, Boa Vista, Recife

EJN - Faculdade Joaquin Nace Av Guararapes, 233, Santo António, Recife
Figura 3: Programação da III Semana de Comunicação Pública de Pernambuco. Fonte: Os autores. 
contato foi estabelecido para convidar cada uma das instituições a inserir a comunicação pública como uma disciplina nos currículos escolares, a enviar material produzido pelos cursos para a veiculação nas emissoras públicas, e a participar da realização da III Semana de Comunicação Pública de Pernambuco.

Em três reuniões envolvendo os coordenadores dos diversos cursos de Recife, Olinda e Caruaru - fato inédito - foi montada uma programação composta por uma diversidade de temas que pudesse suscitar o interesse dos estudantes de cada instituição e relacionado ao foco geral do evento que seria "regulamentar a mídia para democratizar o Brasil". Entendendo a necessidade de regulamentação infraconstitucional como passo fundamental ao alcance das condições mínimas de respeito ao direito à comunicação e ao sucesso do recente sistema público de radiodifusão, várias mesas levaram esse objetivo em consideração, com adaptações a depender dos recortes e dos debatedores convidados. Ao todo foram planejadas nove mesas em horários que pudessem contar com a presença dos estudantes e que preferencialmente não colidissem entre si, para que fosse possível aos participantes conferir os debates em diversos lugares.

As tarefas foram divididas da seguinte maneira: as decisões sobre o conceito, as estratégias, as mesas e os palestrantes foram tomadas de forma coletiva com o NTVRU e os representantes de cada curso presentes num colegiado organizador; o NTVRU assumiu a tarefa de articulação dos realizadores, realização da mesa de abertura, inscrição, produção das peças e gestão da divulgação através do site e perfis nas redes sociais; coube a cada curso a organização das suas respectivas mesas, no que diz respeito à logística de convidados, espaço, cobertura, e principalmente divulgação interna com os estudantes.

E os resultados da realização do evento nesse novo formato foram surpreendentes. A divulgação começou com 40 dias de antecedência numa mobilização conjunta com os diversos cursos e instituições, e contou com publicações de textos, vídeos e imagens sobre comunicação pública, além de postagens sobre as mesas e o compartilhamento em grupos e páginas de interesse correlacionado aos temas das mesas. Foram 53 posts que alcançaram o total de 79.221 pessoas e no período de 26 de março a 4 de maio. A página recebeu 938 curtidas a mais, triplicando o número de seguidores. Mais uma vez, foram produzidas chamadas para veiculação na Universitária FM e na TVU Recife, um programa Opinião Pernambuco especial foi ao ar na TVU Recife ao vivo com o tema e convidados da Semana, e a agência experimental Usina, ligada ao curso de design do Centro Acadêmico do Agreste da UFPE colaborou mais uma vez com a produção das peças de divulgação.

Em quatro dias de atividades, a III Semana ofereceu nove mesas que contaram com a participação de 36 palestrantes e 1.500 participantes, do total de 2.085 inscritos. Houve intérprete de libras e a transmissão on line do evento em algumas mesas que somaram mais mil acessos no YouTube, além da produção de conteúdo por parte de algumas instituições que repercutiram em um interprograma de televisão realizado pelo DCom/UFPE e um programa radiofônico especial sobre comunicação pública realizado pela Unicap. Os auditórios estiveram lotados na maioria das instituições, que mobilizaram seus estudantes e professores a integrar as aulas às mesas e oficinas. Os debates envolveram editais públicos de produção audiovisual, saúde e comunicação, direitos autorais, e principalmente a questão da regulamentação da mídia e da democracia, levando a muita gente pela primeira vez essa discussão de forma mais aprofundada.

Reflexo do esforço de articulação, o NTVRU conseguiu atrair para a mesa de abertura além do reitor da UFPE, o secretário do Audiovisual do Ministério da Cultura, o presidente da Empresa Brasil de Comunicação, a coordenadora geral do FNDC e ovice-prefeito da Cidade do Recife. Nesse momento, foram convidados todos os coordenadores dos cursos integrantes da organização, que assinaram um compromisso público de oferta de uma disciplina de comunicação pública, institucionalizando a presença dessa discussão de forma pioneira em grande parte das faculdades de Recife, Olinda e Caruaru.

Tendo em vista a amplitude do evento em 2015, foi estruturado também um formulário de pesquisa, através do modelo do Google, para que os participantes pudessem avaliar a Semana e fornecer dados aos organizadores para melhorias em outras edições. $O$ convite à participação foi feito no e-mail de envio do certificado ao participante e nele estavam sendo avaliadas as atividades em relação ao conteúdo, à infraestrutura, à organização, e o questionamento a respeito do canal de divulgação utilizado para conhecer o evento.

A história trienal da Semana de Comunicação Pública de Pernambuco, portanto, aponta algumas estratégias que, tendo em vista as especificidades locais, repercutiram para um maior envolvimento e sensibilização da população pernambucana com o assunto, a partir da aproximação com os espaços de formação em comunicação social, como estratégia para o fortalecimento do sistema público de radiodifusão, com participação e controle pela sociedade civil. 


\section{Referências}

ANGEIRAS, Maria Clara de Azêvedo. Televisão e educação: história da criação da primeira TV Educativa do Brasil - TV Universitária, Canal 11. 2015. 214 f. Dissertação (Mestrado em Educação) - Programa de PósGraduação em Educação, Departamento de Educação, UFPE, Recife, 2015.

BRASIL. Lei 11.652/08, de 7 de abril de 2008. Disponível em: <http://www.planalto.gov.br/ccivil_03/_ato20072010/2008/lei//11652.htm>. Acesso em: 12 abr. 2016.

EMPRESA BRASIL DE COMUNICAÇÃO. Participação da Sociedade na EBC. Disponível em: <http://conteudo. ebc.com.br/portal/projetos/2015/participacao/index. html>. Acesso em: 12 abr. 2016.

FERREIRA NETO, Haymone Leal. Jornal de quem? Um estudo de caso sobre o Nosso Jornal, da TV Universitária do Recife. 2012. 168 f. Dissertação (Mestrado em Comunicação) - Programa de Pós-Graduação em Comunicação, Departamento de Comunicação Social, UFPE, Recife, 2012.

INTERVOZES. Sistemas públicos de comunicação no mundo: experiências de doze países e o caso brasileiro. São Paulo: Paulus, Intervozes, 2009.

MENDEL, Toby; SOLOMON, Eve. Liberdade de expressão e regulação da radiodifusão. Brasília: Unesco, 2011.
NTVRU. Missão e visão do Núcleo de Televisão

e Rádios Universitárias da UFPE. Disponível em $<$ http://ntvru.ufpe.br/index.php?option=com content $\&$ view $=$ article\&id=108\&ltemid=71>. Acesso em: 11 abr. 2016.

Notas

1 Este texto foi produzido com a colaboração de Aline Lopes Cavalcanti, graduada em Direito pelo Centro Universitário de João Pessoa (UNIPÊ) (Rodovia BR-230, KM 22, s/n, João Pessoa/ PB, 58053-000). E-mail: aline. lopes08@gmail.com.

2 Doutora em Comunicação pela Universidade de São Paulo (USP). Professora da UFPE (Avenida Norte, 68, Recife/PE, Brasil, CEP: 50670-901). E-mail: pathorta@ gmail.com.

3 Mestre em Extensão Rural e Desenvolvimento Local pela Universidade Federal Rural de Pernambuco. Operador de Câmera de Cinema e TV da UFPE (Avenida Norte, 68, Recife/PE, Brasil, CEP: 50670-901). E-mail: perescalheiros@gmail.com. 